OPEN ACCESS

Edited by:

Goran Bajic,

Icahn School of Medicine at Mount

Sinai, United States

Reviewed by: Nirianne Querijero Palacpac,

Osaka University, Japan

Linda Ann Spatz,

City University of New York, United States

${ }^{*}$ Correspondence:

Daniel Lingwood

dlingwood@mgh.harvard.edu

Specialty section:

This article was submitted to Vaccines and Molecular Therapeutics,

a section of the journal

Frontiers in Immunology

Received: 12 May 2021 Accepted: 23 November 2021 Published: 09 December 2021

Citation:

Sangesland M and Lingwood D (2021)

Public Immunity: Evolutionary

Spandrels for Pathway-Amplifying

Protective Antibodies.

Front. Immunol. 12:708882.

doi: 10.3389/fimmu.2021.708882

\section{Public Immunity: Evolutionary Spandrels for Pathway-Amplifying Protective Antibodies}

\author{
Maya Sangesland and Daniel Lingwood* \\ The Ragon Institute of Massachusetts General Hospital, Massachusetts Institute of Technology, and Harvard University, \\ Cambridge, MA, United States
}

Humoral immunity is seeded by affinity between the B cell receptor (BCR) and cognate antigen. While the BCR is a chimeric display of diverse antigen engagement solutions, we discuss its functional activity as an 'innate-like' immune receptor, wherein genetically hardwired antigen complementarity can serve as reproducible templates for pathwayamplifying otherwise immunologically recessive antibody responses. We propose that the capacity for germline reactivity to new antigen emerged as a set of evolutionary spandrels or coupled traits, which can now be exploited by rational vaccine design to focus humoral immunity upon conventionally immune-subdominant antibody targets. Accordingly, we suggest that evolutionary spandrels account for the necessary but unanticipated antigen reactivity of the germline antibody repertoire.

Keywords: B cells, broadly neutralizing antibodies, vaccination, immunity, evolution

\section{THE BCR AS A FUNCTIONALLY ADAPTIVE IMMUNE RECEPTOR}

It has been more than 100 years since Paul Ehrlich's proposal of immune receptors with distinct antigen specificities (1-3), from which the B cell antigen receptor (BCR) has emerged as a cornerstone of adaptive immunity. This highly diversified ligand binding surface enables functional adaptation, facilitating the accommodation of essentially any antigen. Receptor diversity is achieved through recombination of antibody V, D and J gene segments during B cell development, resulting in a vast plurality of BCR-antigen binding sites, each unique to an individual $\mathrm{B}$ cell clone $(4,5)$. Each binding site is composed of six antigen-engaging loops or complementarity determining regions (CDRs) in which the centrally positioned hypervariable CDR3 loops on the heavy and light chains are surrounded by CDRs encoded by antibody $\mathrm{V}$ region genes (6-11) (Figure 1A). During antibody recombination, $\mathrm{N}$-junctional diversification between the antibody $\mathrm{V}$, $\mathrm{D}$ and $\mathrm{J}$ gene segments concentrates BCR diversity within the heavy chain CDR3 (CDRH3), which in conjunction with combinatorial assortment of the gene-encoded CDRs, results in a germline repertoire of $\sim 10^{12}$ unique antigen binding sites (12-14). Hypervariable CDRH3 diversity thus enables functionally adaptive complementarity against previously 'unseen' molecular targets (13, $15,16)$. 


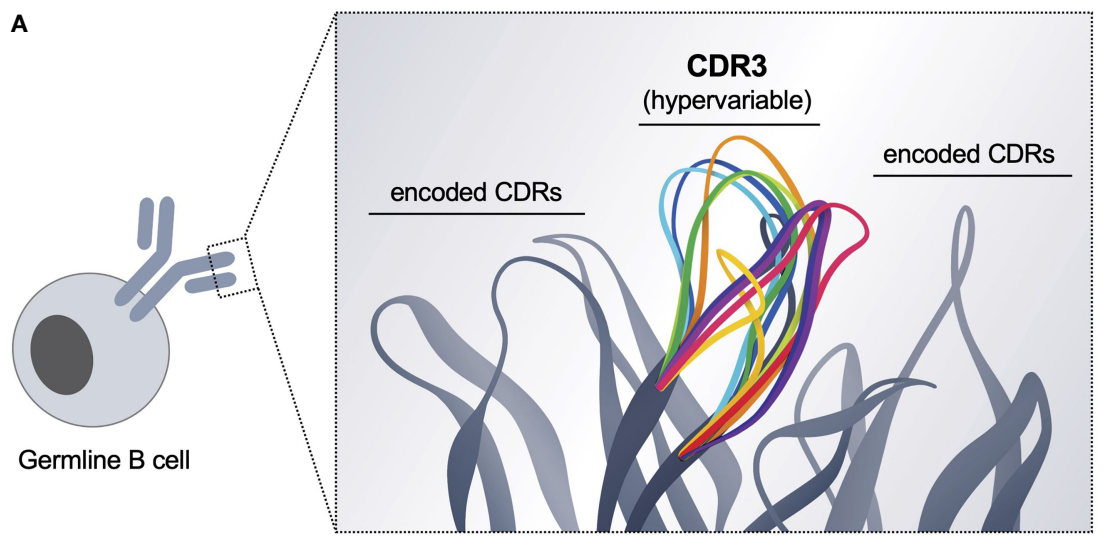

B Functionally Adaptive Antigen Recognition
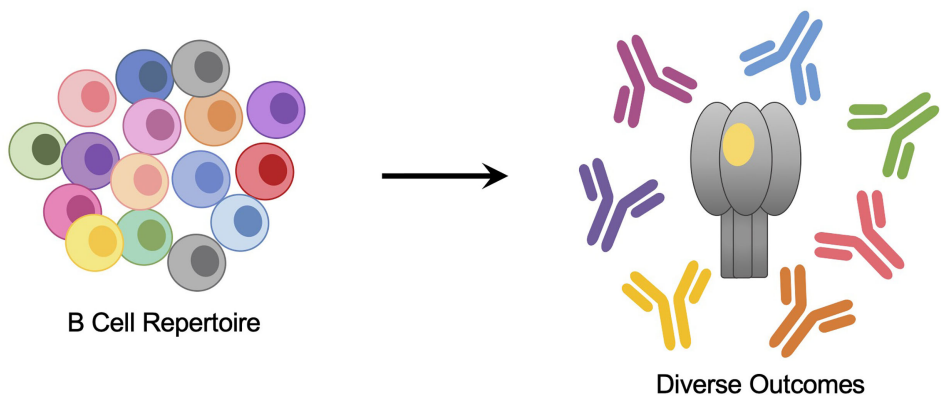

C Gene-Endowed Antigen Recognition

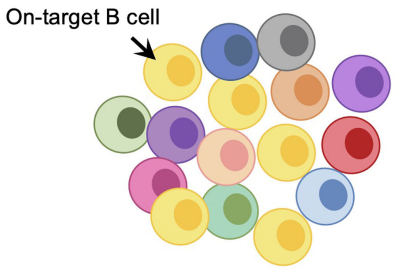

B Cell Repertoire (elevated frequency of on-target precursors)

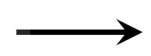

Reproducible Engagement and Expansion

FIGURE 1 | The antigen-binding surface of the germline BCR harbors functionally adaptive and 'innate-like' antigen targeting solutions. (A) The antigen-binding site of the germline BCR is formed by antibody $\vee$ gene-encoded CDRs and hypervariable CDR3s that are centrally positioned. BCR diversity is a product of combinatorial assortment of the gene-encoded CDR repertoire and stochastic $\mathrm{N}$-junctional diversification, which generates deep plurality in the CDR3. (B) As diversity is concentrated within the hypervariable CDR3, these loops are the principal source of binding energy to engage new antigen, providing functionally adaptive antigen receptor activity. However, If CDR3-centered targeting solutions are rare, then the corresponding on-target BCRs will be poorly expanded following immune challenge. (C) Gene-endowed antigen recognition can occur when specific encoded CDRs supply reproducible and deterministic specificity to a target epitope. This reproducibility can be exploited to 'pathway-amplify' otherwise immunologically subdominant vaccine responses.

\section{GENE-ENDOWED BCR-ANTIGEN COMPLEMENTARITY}

In addition to the BCR's adaptive immunoreceptor activity, geneencoded CDRs have long-been hypothesized to endow hardwired affinity for specific antigen substrates (17-19). Such activity was initially observed as the constrained use of a single antibody $\mathrm{V}_{\mathrm{H}}$ gene by hybridomas reactive to the head group of the eukaryotic and bacterial lipid phosphorylcholine (PC) $(20,21)$, a gene-encoded antigen specificity that is now recognized to impart anti-septic activity to natural antibodies, polyreactive immunoglobulins that circulate at high titer due to constitutive production (22-24). Nonrandom use of specific antibody $\mathrm{V}$ gene-encoded CDRs have since been found to underscore humoral immunity against diverse 
antigen input (25-34), including certain vaccine targets, which results in genetically reproducible or 'public' antibody responses with neutralizing activity against numerous pathogens, including influenza virus, HIV, hepatitis $\mathrm{C}$ virus, hepatitis B virus, yellow fever virus, respiratory syncytial virus, cytomegalovirus, SARS-CoV-2 and the malaria parasite Plasmodium falciparum (27, 35-56). Such responses are considered deterministic and 'public' because the structure of the antibody binding site is constrained to specific gene-encoded CDRs, enabling reproducible reconstruction of the same antibody within different individuals. While gene-encoded CDRs are structurally limited to a few 'canonical' loop conformations $(11,57,58)$, they are not functionally redundant, as we have recently demonstrated using HC2 humanized mice, where antibody responses are constrained to single human $\mathrm{V}_{\mathrm{H}}$ genes but also bear unconstrained human-like CDRH3 diversity (59-61). These studies demonstrate that specific antibody $\mathrm{V}_{\mathrm{H}}$ gene input to the repertoire is required for germline $\mathrm{B}$ cells to accommodate and respond to select epitopes and/or entire antigen geometries in vivo (59-62). Hence, BCR substrate specificity can be both functionally adaptive (CDRH3 dominant) and genetically programmed (antibody $\mathrm{V}$ gene constrained). The latter forms the basis of gene-endowed B cell antigen recognition.

$\mathrm{B}$ cell receptor signaling is also tightly integrated with innate immune signals. After ligation of Toll-like receptors, conventional innate immune receptors for pathogen-associated molecular patterns (PAMPs), B cell proliferation also requires BCR-dependent signaling to occur in parallel (63), consistent with BCR triggering as a tonic survival signal $(64,65)$.

\section{GENE-ENDOWED ANTIGEN RECOGNITION AS REPRODUCIBLE SUBSTRATE FOR GERMLINE STIMULATING VACCINES}

Hypervariable viruses such as HIV and influenza continue to defy conventional vaccine approaches (66-69). Indeed, a major obstacle to eliciting broadly protective responses is largely attributed to the fact that the surface antigens of these viruses establish complex immunodominance hierarchies that effectively distract the host antibody response away from functionally conserved sites of vulnerability, both following infection or vaccination (62, 70-75). It is well established that the strength of an antibody response against a given epitope is, in part, a function of the proportion and cognate affinities of the corresponding on-target BCRs present within the germline B cell repertoire (59, 60, 62, 76-82). Ontarget BCRs refer to germline antibodies bearing affinity for a desired epitope (e.g. a conserved site of vulnerability on the surface glycoproteins of HIV or influenza virus), whereas offtarget BCRs engage different epitopes on the same antigen (the otherwise hypervariable features in the case of 'vaccine resisting' viruses). Immunodistraction by HIV and influenza viral antigens can occur when the on-target BCRs fail to compete with off-target BCRs, allowing the latter to dominate affinity maturation within B cell germinal center reactions, which subsequently carries over into downstream B cell memory and serum antibody responses $(59,60$,
62, 76-83). Germline stimulating vaccines, particularly in the HIV space, have focused on engineering enhanced immunogen affinity to specific on-target BCRs that are known precursors for broadly neutralizing antibodies (bnAbs) $(76,77,79,84-100)$. These approaches have provided proof of concept for selective priming and expansion of human B cell lineages, both within human BCRknock in mice $(84-88,91-93,95,97,99-101)$ and within mice bearing adoptively transferred bnAb precursors at diluted $\mathrm{B}$ cell frequencies $(76,77,79,80,89,98)$. Consequently, a leading germline stimulating HIV vaccine candidate is currently under clinical evaluation (Clinical Trials Identifier: NCT03547245).

Importantly, gene-endowed BCR antigen recognition provides natural reproducibility in epitope-targeting that can bolster the proportion of on-target BCRs present within the antigen naïve $\mathrm{B}$ cell repertoire (Figures 1B, C). The centrally positioned CDRH3 is by definition hypervariable (12-15). Thus bnAb precursors with CDRH3-dominant contacts will be difficult to selectively target and expand by germline stimulating immunogens, particularly if they are rare; although recent advances in protein engineering have made exciting headway in addressing this issue $(80,102)$. By contrast, the paratopes of human antibody gene-endowed bnAbs, both against HIV and influenza virus, are dominated by genetically encoded CDRs $(35,37,38,45,53,103,104)$, indicative of a reproducible, deterministic source of on-target-specificity that may be expanded by vaccination. Most germline stimulating concepts have therefore focused on bnAb pathways that involve antibody gene-endowed antigen contact, as reflected by the heavy emphasis on vaccineelicitation of human VRC01-class bnAbs which rely on usage of the antibody $\mathrm{V}_{\mathrm{H}}$ gene IGHV1-2*02 $(76,77,79,84-101)$.

Using the HC2 mouse system, we have shown that individual human $\mathrm{V}_{\mathrm{H}}$ genes do indeed selectively endow the polyclonal BCR repertoire with natural germline specificity for select epitopes $(59,60$, $62)$. We found that in contrast to other human $\mathrm{V}_{\mathrm{H}}$ genes, IGHV1$69^{\star} 01$ endows the otherwise unconstrained human-like BCR repertoire with the capacity to engage a conserved site of vulnerability on the surface of the major influenza viral spike protein hemagglutinin $(59,60,62)$. This gene-endowed affinity provided substrate for reproducible pathway-amplification of broadly protective influenza bnAb responses which were elicited using a single rationally designed hemagglutinin immunogen $(59,60,62)$. Importantly, the capacity to pathway-amplify influenza bnAbs was directly proportional to the frequency of IGHV1-69*01 B cells present within the repertoire, a parameter that could be genetically diluted in the HC2 system (59). This dose response-relationship further reveals a deterministic/gene-programmed antigen recognition activity by $\mathrm{B}$ cells and demonstrates how public humoral immunity can serve as a reproducible template for selectively amplifying antibody responses that engage otherwise unseen vaccine targets.

\section{GENE-ENDOWED ANTIGEN RECOGNITION AS SPANDRELS OF EVOLUTION}

How might we place vaccine-amplifiable public immunity within the context of evolution? Undoubtedly the repertoire was shaped 
by positive selection $(17-19,27)$, and it is tempting to speculate that specific antibody $\mathrm{V}$ genes were retained to enable recognition against specific pathogens or groups of pathogens. However, it will be difficult to demonstrate that any one particular antibody $\mathrm{V}$ gene sequence was selected due to an immediate fitness benefit, as would be required for an evolutionary adaptation (105-107). Moreover, unless public bnAb responses (such as those against HIV and influenza virus) are selectively triggered and pathwayamplified by rationally designed vaccines, their benefit to combating infection at 'steady-state' is not clear. Gene-endowed antigen recognition also enables public human neutralizing antibody responses against more recently emerged pathogens, such as HIV $(35,45,108)$ and SARS-CoV-2 (50, 54, 55), arguing against an evolutionarily adaptive relationship. Indeed, using HC2 humanized mice, we demonstrated that the IGHV1$2^{\star} 02 \mathrm{~V}_{\mathrm{H}}$ sequence utilized in public VRC01-class HIV bnAbs, also endows the germline BCR repertoire with the capacity to engage the conserved saccrolipid core of LPS, a 'primordial' but key surface antigen from gram-negative bacteria (61). This underscores the notion of broad germline utility $(27,28,32)$, which we propose is best placed within the framework of evolutionary spandrels.

A term famously borrowed by Gould and Lewontin, a spandrel is an unplanned architectural feature that forms as an engineering constraint during the construction of domed cathedrals and was used to designate evolutionary characteristics that arise in the absence of direct selection and are byproducts of another 'decision' in design $(109,110)$ (Figure 2A). The importance of evolutionary spandrels in shaping biological form and function has been observed across many scales (107, 110-114). At the animal level, a classical example is in female spotted hyenas, where muscularized genitalia has been viewed as an evolutionary byproduct resulting from elevated testosterone, an endocrine adaptation associated with superior size and female dominance (110). At the molecular scale, evolutionary spandrels have accounted for structural coupling between protein folding and emergence of affinity to novel binding partners (114). Such coupled traits can appear in the absence of an immediate fitness
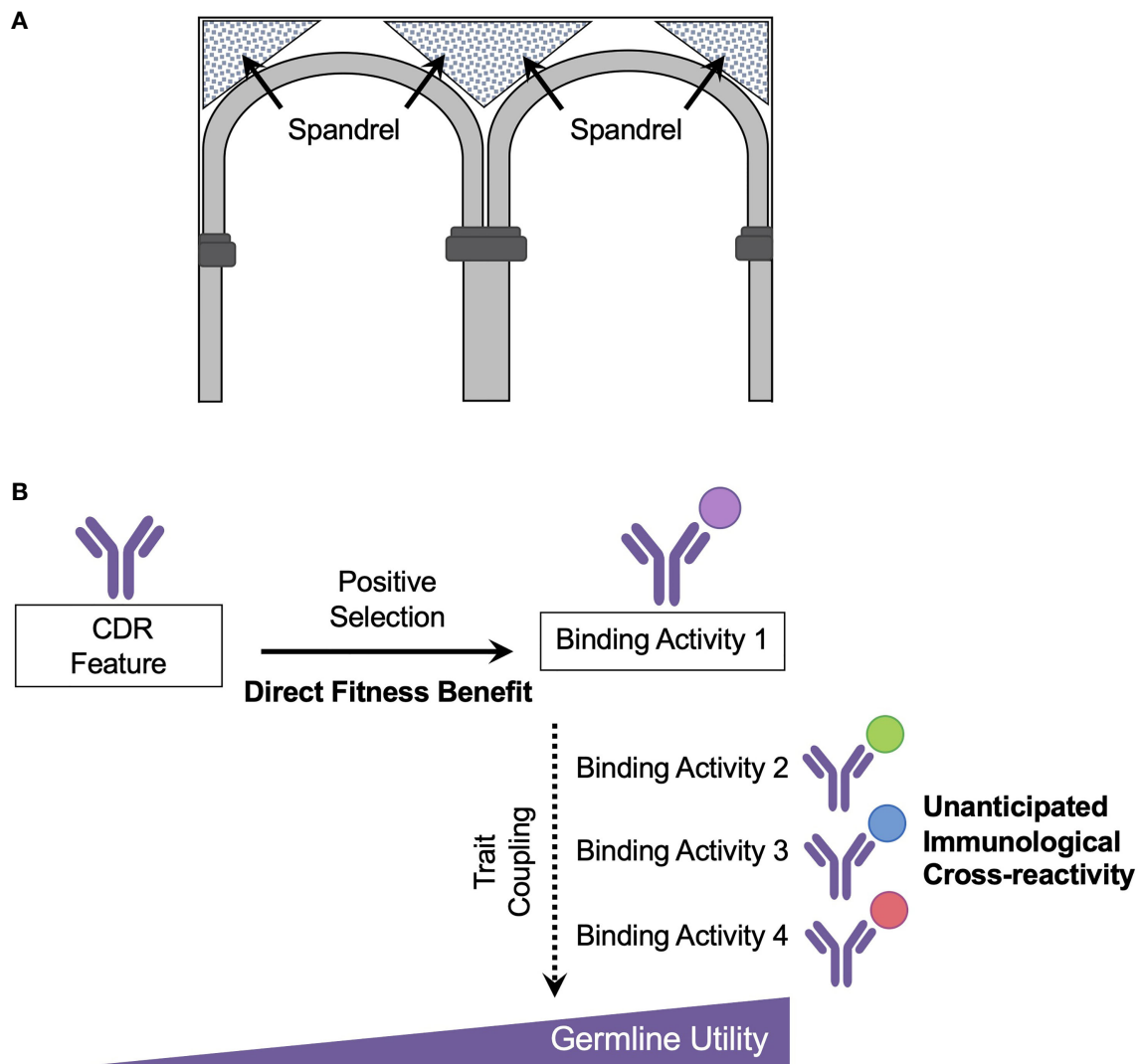

FIGURE 2 | Recognition of new antigen as an evolutionary spandrel (A) A spandrel is an architectural by-product formed by adjacent rounded arches within a rectangular frame. (B) Germline antibody reactivity and utility is proposed to emerge as a set of spandrels or secondary 'unintended' consequences of positive selection on the germline antibody repertoire. In this scheme, the antibody repertoire was initially shaped by positive selection for combating disease-causing pathogens. A key evolutionary adaptation in this process was the development of recombinatorial lymphocyte immune receptors, which appeared in vertebrates $\sim 500$ mya ago. However, germline antibody reactivity to new, different, antigen cannot be considered as an evolutionary adaptation unless they result in an increase in inclusive fitness. Rather the capacity for reactivity to novel antigen (hen egg lysosome, ovalbumin, vaccine antigens) is more appropriately framed as spandrels or unanticipated biproducts of the primary adaptations which shaped the antibody repertoire over evolutionary time. A case example are genetically encoded CDRs which show reproducible usage for engaging bnAb targets on 'historical' viruses such as influenza virus and on more recently emerged viruses such as HIV and SARS-CoV-2. 
benefit and may provide 'unanticipated' utilities. We suggest that germline antibody responsiveness, and hence the potential for 'unplanned' immune reactivity to previously unseen antigen, is explained by this same evolutionary principle (Figure 2B).

Recombinatorial lymphocyte immune receptors appeared in vertebrates $\sim 500$ mya ago and likely emerged as a key evolutionary adaptation (or series of adaptations) leading to positive selection (115-117). In jawed vertebrates, VDJ recombination supplies germline BCR diversification, and in jawless vertebrates, the functionally analogous variable lymphocyte receptors (VLRs) are diversified via recombination of leucine-rich-repeat gene modules $(118,119)$. However, germline reactivity and cross-reactivity to new 'unanticipated' antigens (e.g. present-day vaccines) will be an unplanned consequence of these diversification processes, which have been pre-shaped over evolutionary time. Thus within an evolutionary framework, the capacity for germline antibody responsiveness and cross-reactivity to incoming antigen should be considered as a side effect or spandrel. Included here will be the public antibody contact solutions that endow for genetically reproducible human bnAb responses that require rational vaccine engineering for selective triggering and pathway-amplification (Figure 2B). Unless the specific germline encoded response to antigen can be demonstrated as evolutionarily adaptive, i.e. provided an increase in inclusive fitness (105-107), its emergence is best described as an unanticipated utility.

Evolutionary spandrels as a means of developing 'unplanned' utility in antigen recognition may also have fueled the "tonic" BCR-dependent signaling required to coordinate B cell survival and proliferation with activation signals triggered by PAMPs and T cell ligands (63-65). Such coupling between innate and adaptive immune reactions will be critical for both adjuvating $\mathrm{B}$ cell activation and linking $\mathrm{T}$ cell help during the humoral response.

\section{PERSPECTIVE}

Due to its genetic reproducibility, gene-endowed antigen recognition can increase the likelihood of engaging certain

\section{REFERENCES}

1. Ehrlich P. Die Wertbemessung Des Diphterie- Heilserums Und Deren Theoretische Grundlagen. Klinisches Jahrbuch (1897) 6:299-326.

2. Ehrlich P. Croonian Lecture: On Immunity With Special Reference to Cell Life. Proc R Soc London (1900) 66:424-48. doi: 10.1098/rspl.1899.0121

3. Ehrlich P. Die Seitenkettentheorie Der Immunität. Anleitung $\mathrm{Zu}$ Hygienischen Untersuchungen: Nach Den Im Hygienischen Institut Der Königl. Ludwig-Maximilians-Universität zu München üblichen Methoden zusammengestellt 3 Aufl. (1902) 3:381-94.

4. Jung D, Alt FW. Unraveling V(D)J Recombination; Insights Into Gene Regulation. Cell (2004) 116(2):299-311. doi: 10.1016/S0092-8674(04)00039-X

5. Nicolas L, Cols M, Choi JE, Chaudhuri J, Vuong B. Generating and Repairing Genetically Programmed DNA Breaks During Immunoglobulin Class Switch Recombination. F1000Res (2018) 7:458. doi: 10.12688/ f1000research.13247.1

6. Morea V, Tramontano A, Rustici M, Chothia C, Lesk AM. Conformations of the Third Hypervariable Region in the VH Domain of Immunoglobulins. J Mol Biol (1998) 275(2):269-94. doi: 10.1006/jmbi.1997.1442

7. Oliva B, Oliva B, Bates PA, Querol E, Aviles FX, Sternberg MJ. Automated Classification of Antibody Complementarity Determining Region 3 of the epitopes or antigenic configurations, providing a framework to rationally overcome the immunological subdominance of some antigenic targets. Proof-of-concept studies in the pre-clinical space indicate that this unconventional mode of $\mathrm{B}$ cell antigen engagement can be exploited to pathway-amplify genetically reproducible antibody targeting solutions against otherwise difficult to perceive sites of vulnerability on vaccine-resistant pathogens and is thus poised for more comprehensive clinical evaluation. The capacity for pathway-amplification most likely arose as an evolutionary spandrel or secondary consequence of how the antibody repertoire was shaped over evolutionary time. The evolutionarily non-adaptive manner through which spandrels emerge will likely ensure continued discovery of gene-endowed antibody responses against specific vaccine targets, and as a consequence, the corresponding publicly reproducible antibody development pathways that may be judiciously activated and amplified by vaccination.

\section{AUTHOR CONTRIBUTIONS}

MS and DL wrote the manuscript. All authors contributed to the article and approved the submitted version.

\section{FUNDING}

DL was supported by the NIH (R01AI137057, DP2DA042422, R01AI124378, R01AI153098, R01AI155447), the Harvard University Milton Award, and The Gilead Research Scholars Program Institute. MS was supported by an NIH fellowship (F31Al138368).

\section{ACKNOWLEDGMENTS}

The authors thank Arup Chakraborty for helpful discussion.

Heavy Chain (H3) Loops Into Canonical Forms and Its Application to Protein Structure Prediction. J Mol Biol (1998) 279(5):1193-210. doi: 10.1006/jmbi.1998.1847

8. Shirai H, Kidera A, Nakamura H. H3-Rules: Identification of CDR-H3 Structures in Antibodies. FEBS Lett (1999) 455(1-2):188-97. doi: 10.1016/ S0014-5793(99)00821-2

9. Kuroda D, Shirai H, Kobori M, Nakamura H. Structural Classification of CDR-H3 Revisited: A Lesson in Antibody Modeling. Proteins (2008) 73 (3):608-20. doi: 10.1002/prot.22087

10. Saada R, Weinberger M, Shahaf G, Mehr R. Models for Antigen Receptor Gene Rearrangement: CDR3 Length. Immunol Cell Biol (2007) 85(4):32332. doi: $10.1038 /$ sj.icb.7100055

11. North B, Lehmann A, Dunbrack RL Jr. A New Clustering of Antibody CDR Loop Conformations. J Mol Biol (2011) 406(2):228-56. doi: 10.1016/ j.jmb.2010.10.030

12. Briney B, Weinberger M, Shahaf G, Mehr R. Commonality Despite Exceptional Diversity in the Baseline Human Antibody Repertoire. Nature (2019) 566(7744):393-7. doi: 10.1038/s41586-019-0879-y

13. Schroeder HW Jr, Cavacini L. Structure and Function of Immunoglobulins. J Allergy Clin Immunol (2010) 125(2 Suppl 2):S41-52. doi: 10.1016/ j.jaci.2009.09.046 
14. Mora T, Walczak AM. How Many Different Clonotypes Do Immune Repertoires Contain? Curr Opin Syst Biol (2019) 18:104-10. doi: 10.1016/ j.coisb.2019.10.001

15. Xu JL, Davis MM. Diversity in the CDR3 Region of V(H) Is Sufficient for Most Antibody Specificities. Immunity (2000) 13(1):37-45. doi: 10.1016/ S1074-7613(00)00006-6

16. Sok D, Le KM, Vadnais M, Saye-Francisco KL, Jardine JG, Torres JL, et al. Rapid Elicitation of Broadly Neutralizing Antibodies to HIV by Immunization in Cows. Nature (2017) 548(7665):108-11. doi: 10.1038/ nature23301

17. Chothia C, Lesk AM. Canonical Structures for the Hypervariable Regions of Immunoglobulins. J Mol Biol (1987) 196(4):901-17. doi: 10.1016/0022-2836 (87)90412-8

18. Chothia C, Lesk AM, Tramontano A, Levitt M, Smith-Gill SJ, Air G, et al. Conformations of Immunoglobulin Hypervariable Regions. Nature (1989) 342(6252):877-83. doi: 10.1038/342877a0

19. Cohn M, Langman RE. The Protecton: The Unit of Humoral Immunity Selected by Evolution. Immunol Rev (1990) 115:11-147. doi: 10.1111/j.1600065X.1990.tb00783.x

20. Crews S, Griffin J, Huang H, Calame K, Hood L. A Single VH Gene Segment Encodes the Immune Response to Phosphorylcholine: Somatic Mutation Is Correlated With the Class of the Antibody. Cell (1981) 25(1):59-66. doi: 10.1016/0092-8674(81)90231-2

21. Gearhart PJ, Johnson ND, Douglas RL, Hood L. IgG Antibodies to Phosphorylcholine Exhibit More Diversity Than Their IgM Counterparts. Nature (1981) 291(5810):29-34. doi: 10.1038/291029a0

22. Holodick NE, Rodriguez-Zhurbenko N, Hernandez AM. Defining Natural Antibodies. Front Immunol (2017) 8:872. doi: 10.3389/fimmu.2017.00872

23. Savage HP, Baumgarth N. Characteristics of Natural Antibody-Secreting Cells. Ann N Y Acad Sci (2015) 1362:132-42. doi: 10.1111/nyas.12799

24. Mi QS, Zhou L, Schulze DH, Fischer RT, Lustig A, Rezanka LJ, et al. Highly Reduced Protection Against Streptococcus Pneumoniae After Deletion of a Single Heavy Chain Gene in Mouse. Proc Natl Acad Sci USA (2000) 97 (11):6031-6. doi: 10.1073/pnas.110039497

25. Willis JR, Briney BS, DeLuca SL, Crowe JE Jr, Meiler J. Human Germline Antibody Gene Segments Encode Polyspecific Antibodies. PloS Comput Biol (2013) 9(4):e1003045. doi: 10.1371/journal.pcbi.1003045

26. Kirik U, Persson H, Levander F, Greiff L, Ohlin M. Antibody Heavy Chain Variable Domains of Different Germline Gene Origins Diversify Through Different Paths. Front Immunol (2017) 8:1433. doi: 10.3389/ fimmu.2017.01433

27. Lerner RA. Rare Antibodies From Combinatorial Libraries Suggests an S.O.S. Component of the Human Immunological Repertoire. Mol Biosyst (2011) 7(4):1004-12. doi: 10.1039/c0mb00310g

28. Henry Dunand CJ, Wilson PC. Restricted, Canonical, Stereotyped and Convergent Immunoglobulin Responses. Philos Trans $R$ Soc Lond B Biol Sci (2015) 370(1676):20140238. doi: 10.1098/rstb.2014.0238

29. Hwang KK, Trama AM, Kozink DM, Chen X, Wiehe K, Cooper AJ, et al. IGHV1-69 B Cell Chronic Lymphocytic Leukemia Antibodies Cross-React With HIV-1 and Hepatitis C Virus Antigens as Well as Intestinal Commensal Bacteria. PloS One (2014) 9(3):e90725. doi: 10.1371/ journal.pone.0090725

30. Pape KA, Maul RW, Dileepan T, Paustian AS, Gearhart PJ, Jenkins MK. Naive B Cells With High-Avidity Germline-Encoded Antigen Receptors Produce Persistent IgM(+) and Transient IgG(+) Memory B Cells. Immunity (2018) 48(6):1135-43.e4. doi: 10.1016/j.immuni.2018.04.019

31. Brorson K, Thompson C, Wei G, Krasnokutsky M, Stein KE. Mutational Analysis of Avidity and Fine Specificity of Anti-Levan Antibodies. J Immunol (1999) 163(12):6694-701.

32. Lonberg N. Human Antibodies From Transgenic Animals. Nat Biotechnol (2005) 23(9):1117-25. doi: 10.1038/nbt1135

33. Schickel JN, Glauzy S, Ng YS, Chamberlain N, Massad C, Isnardi I, et al. SelfReactive VH4-34-Expressing IgG B Cells Recognize Commensal Bacteria. J Exp Med (2017) 214(7):1991-2003. doi: 10.1084/jem.20160201

34. Lucas AH, Langley RJ, Granoff DM, Nahm MH, Kitamura MY, Scott MG. An Idiotypic Marker Associated With a Germ-Line Encoded Kappa Light Chain Variable Region That Predominates the Vaccine-Induced Human
Antibody Response to the Haemophilus Influenzae B Polysaccharide. J Clin Invest (1991) 88(6):1811-8. doi: 10.1172/JCI115502

35. Zhou T, Lynch RM, Chen L, Acharya P, Wu X, Doria-Rose NA, et al. Structural Repertoire of HIV-1-Neutralizing Antibodies Targeting the CD4 Supersite in 14 Donors. Cell (2015) 161:1280-92. doi: 10.1016/ j.cell.2015.05.007

36. Flyak AI, Ruiz S, Colbert MD, Luong T, Crowe JE Jr, Bailey JR, et al. HCV Broadly Neutralizing Antibodies Use a CDRH3 Disulfide Motif to Recognize an E2 Glycoprotein Site That Can Be Targeted for Vaccine Design. Cell Host Microbe (2018) 24(5):703-16.e3. doi: 10.1016/j.chom.2018.10.009

37. Lingwood D, McTamney PM, Yassine HM, Whittle JR, Guo X, Boyington JC, et al. Structural and Genetic Basis for Development of Broadly Neutralizing Influenza Antibodies. Nature (2012) 489(7417):566-70. doi: 10.1038 /nature 11371

38. Joyce MG, Wheatley AK, Thomas PV, Chuang GY, Soto C, Bailer RT, et al Vaccine-Induced Antibodies That Neutralize Group 1 and Group 2 Influenza A Viruses. Cell (2016) 166(3):609-23. doi: 10.1016/ j.cell.2016.06.043

39. Pappas L, Foglierini M, Piccoli L, Kallewaard NL, Turrini F, Silacci, et al Rapid Development of Broadly Influenza Neutralizing Antibodies Through Redundant Mutations. Nature (2014) 516(7531):418-22. doi: 10.1038/ nature 13764

40. Avnir Y, Tallarico AS, Zhu Q, Bennett AS, Connelly G, Sheehan J. Molecular Signatures of Hemagglutinin Stem-Directed Heterosubtypic Human Neutralizing Antibodies Against Influenza A Viruses. PloS Pathog (2014) 10 (5):e1004103. doi: 10.1371/journal.ppat.1004103

41. Tzarum N, Giang E, Kong L, He L, Prentoe J, Augestad E, et al. Genetic and Structural Insights Into Broad Neutralization of Hepatitis C Virus by Human VH1-69 Antibodies. Sci Adv (2019) 5(1):eaav1882. doi: 10.1126/ sciadv.aav1882

42. Scheid JF, Mouquet H, Ueberheide B, Diskin R, Klein F, Oliveira TY, et al Sequence and Structural Convergence of Broad and Potent HIV Antibodies That Mimic CD4 Binding. Science (2011) 333(6049):1633-7. doi: 10.1126/ science. 1207227

43. Wec AZ, Haslwanter D, Abdiche YN, Shehata L, Pedreno-Lopez N, Moyer $\mathrm{CL}$, et al. Longitudinal Dynamics of the Human B Cell Response to the Yellow Fever 17D Vaccine. Proc Natl Acad Sci USA (2020) 117(12):6675-85. doi: 10.1073/pnas.1921388117

44. Golsaz-Shirazi F, Amiri MM, Bahadori M, Bayat AA, Mohammadi H, Farid $S$, et al. Molecular Characterization of Murine Monoclonal Antibody Variable Regions Specific for Hepatitis B Surface Antigen. Viral Immunol (2015) 28(8):425-33. doi: 10.1089/vim.2015.0023

45. Zhou T, Zhu J, Wu X, Moquin S, Zhang B, Acharya P, et al. Multidonor Analysis Reveals Structural Elements, Genetic Determinants, and Maturation Pathway for HIV-1 Neutralization by VRC01-Class Antibodies. Immunity (2013) 39(2):245-58. doi: 10.1016/j.immuni.2013.04.012

46. Wu X, Zhou T, Zhu J, Zhang B, Georgiev I, Wang C, et al. Focused Evolution of HIV-1 Neutralizing Antibodies Revealed by Structures and Deep Sequencing. Science (2011) 333(6049):1593-602. doi: 10.1126/ science. 1207532

47. Hehle V, Beretta M, Bourgine M, Ait-Goughoulte M, Planchais C, Morisse S, et al. Potent Human Broadly Neutralizing Antibodies to Hepatitis B Virus From Natural Controllers. J Exp Med (2020) 217(10):e20200840. doi: 10.1084/jem.20200840

48. Chen F, Tzarum N, Lin X, Giang E, Velazquez-Moctezuma R, Augestad EH, et al. Functional Convergence of a Germline-Encoded Neutralizing Antibody Response in Rhesus Macaques Immunized With HCV Envelope Glycoproteins. Immunity (2021) 54(4):781-96.e4. doi: 10.1016/ j.immuni.2021.02.013

49. Mukhamedova M, Wrapp D, Shen CH, Gilman MSA, Ruckwardt TJ, Schramm CA, et al. Vaccination With Prefusion-Stabilized Respiratory Syncytial Virus Fusion Protein Induces Genetically and Antigenically Diverse Antibody Responses. Immunity (2021) 54(4):769-80.e6. doi: 10.1016/j.immuni.2021.03.004

50. Yuan M, Liu H, Wu NC, Lee CD, Zhu X, Zhao F, et al. Structural Basis of a Shared Antibody Response to SARS-CoV-2. Science (2020) 369(6507):111923. doi: 10.1126/science.abd2321 
51. Imkeller K, Scally SW, Bosch A, Marti GP, Costa G, Triller G, et al. Antihomotypic Affinity Maturation Improves Human B Cell Responses Against a Repetitive Epitope. Science (2018) 360(6395):1358-62. doi: 10.1126/science.aar5304

52. Murugan R, Buchauer L, Triller G, Kreschel C, Costa G, Pidelaserra Marti G, et al. Clonal Selection Drives Protective Memory B Cell Responses in Controlled Human Malaria Infection. Sci Immunol (2018) 3(20):eaap8029. doi: 10.1126/sciimmunol.aap8029

53. Sui J, Hwang WC, Perez S, Wei G, Aird D, Chen LM, et al. Structural and Functional Bases for Broad-Spectrum Neutralization of Avian and Human Influenza A Viruses. Nat Struct Mol Biol (2009) 16(3):265-73. doi: 10.1038/ nsmb.1566

54. Andreano E, Rappuoli R. Immunodominant Antibody Germlines in COVID-19. J Exp Med (2021) 218(5):e20210281. doi: 10.1084/jem.20210281

55. Robbiani DF, Gaebler C, Muecksch F, Lorenzi JCC, Wang Z, Cho A, et al. Convergent Antibody Responses to SARS-CoV-2 in Convalescent Individuals. Nature (2020) 584(7821):437-42. doi: 10.1038/s41586-0202456-9

56. Thomson CA, Bryson S, McLean GR, Creagh AL, Pai EF, Schrader JW. Germline V-Genes Sculpt the Binding Site of a Family of Antibodies Neutralizing Human Cytomegalovirus. EMBO J (2008) 27(19):2592-602. doi: 10.1038/emboj.2008.179

57. Al-Lazikani B, Lesk AM, Chothia C. Standard Conformations for the Canonical Structures of Immunoglobulins. J Mol Biol (1997) 273(4):92748. doi: 10.1006/jmbi.1997.1354

58. Martin AC, Thornton JM. Structural Families in Loops of Homologous Proteins: Automatic Classification, Modelling and Application to Antibodies. J Mol Biol (1996) 263(5):800-15. doi: 10.1006/jmbi.1996.0617

59. Sangesland M, Ronsard L, Kazer SW, Bals J, Boyoglu-Barnum S, Yousif AS, et al. Germline-Encoded Affinity for Cognate Antigen Enables Vaccine Amplification of a Human Broadly Neutralizing Response Against Influenza Virus. Immunity (2019) 51(4):735-49.e8. doi: 10.1016/ j.immuni.2019.09.001

60. Amitai A, Sangesland M, Barnes RM, Rohrer D, Lonberg N, Lingwood D, et al. Defining and Manipulating B Cell Immunodominance Hierarchies to Elicit Broadly Neutralizing Antibody Responses Against Influenza Virus. Cell Syst (2020) 11(6):573-88.e9. doi: 10.1016/j.cels.2020.09.005

61. Sangesland M, Yousif AS, Ronsard L, Kazer SW, Zhu AL, Gatter GJ, et al. A Single Human VH-Gene Allows for a Broad-Spectrum Antibody Response Targeting Bacterial Lipopolysaccharides in the Blood. Cell Rep (2020) 32 (8):108065. doi: 10.1016/j.celrep.2020.108065

62. Sangesland M, Lingwood D. Antibody Focusing to Conserved Sites of Vulnerability: The Immunological Pathways for 'Universal' Influenza Vaccines. Vaccines (Basel) (2021) 9(2):125. doi: 10.3390/vaccines 9020125

63. Otipoby KL, Waisman A, Derudder E, Srinivasan L, Franklin A, Rajewsky K. The B-Cell Antigen Receptor Integrates Adaptive and Innate Immune Signals. Proc Natl Acad Sci USA (2015) 112(39):12145-50. doi: 10.1073/ pnas. 1516428112

64. Kraus M, Alimzhanov MB, Rajewsky N, Rajewsky K. Survival of Resting Mature B Lymphocytes Depends on BCR Signaling via the Igalpha/beta Heterodimer. Cell (2004) 117(6):787-800. doi: 10.1016/j.cell.2004.05.014

65. Lam KP, Kuhn R, Rajewsky K. In Vivo Ablation of Surface Immunoglobulin on Mature B Cells by Inducible Gene Targeting Results in Rapid Cell Death. Cell (1997) 90(6):1073-83. doi: 10.1016/S0092-8674(00)80373-6

66. Haynes BF, Mascola JR. The Quest for an Antibody-Based HIV Vaccine. Immunol Rev (2017) 275(1):5-10. doi: 10.1111/imr.12517

67. Erbelding EJ, Post D, Stemmy E, Roberts PC, Augustine AD, Ferguson S, et al. A Universal Influenza Vaccine: The Strategic Plan for the National Institute of Allergy and Infectious Diseases. J Infect Dis (2018) 218:347-54. doi: 10.1093/infdis/jiy103

68. Bekker LG, Tatoud R, Dabis F, Feinberg M, Kaleebu P, Marovich M, et al. The Complex Challenges of HIV Vaccine Development Require Renewed and Expanded Global Commitment. Lancet (2020) 395(10221):384-8. doi: 10.1016/S0140-6736(19)32682-0

69. Nachbagauer R, Palese P. Is a Universal Influenza Virus Vaccine Possible? Annu Rev Med (2020) 71:315-27. doi: 10.1146/annurev-med-120617-041310

70. Burton DR, Mascola JR. Antibody Responses to Envelope Glycoproteins in HIV-1 Infection. Nat Immunol (2015) 16(6):571-6. doi: 10.1038/ni.3158
71. Yaseen MM, Yaseen MM, Abuharfeil NM, Alqudah MA, Yaseen MM. Mechanisms and Factors That Drive Extensive Human Immunodeficiency Virus Type-1 Hypervariability: An Overview. Viral Immunol (2017) 30 (10):708-26. doi: 10.1089/vim.2017.0065

72. Nabel GJ, Fauci AS. Induction of Unnatural Immunity: Prospects for a Broadly Protective Universal Influenza Vaccine. Nat Med (2010) 16 (12):1389-91. doi: 10.1038/nm1210-1389

73. Altman MO, Angeletti D, Yewdell JW. Antibody Immunodominance: The Key to Understanding Influenza Virus Antigenic Drift. Viral Immunol (2018) 31(2):142-9. doi: 10.1089/vim.2017.0129

74. Wheatley AK, Kent SJ. Prospects for Antibody-Based Universal Influenza Vaccines in the Context of Widespread Pre-Existing Immunity. Expert Rev Vaccines (2015) 14(9):1227-39. doi: 10.1586/14760584.2015.1068125

75. Altman MO, Bennink JR, Yewdell JW, Herrin BR. Lamprey VLRB Response to Influenza Virus Supports Universal Rules of Immunogenicity and Antigenicity. Elife (2015) 4:e07467. doi: 10.7554/eLife.07467

76. Abbott RK, Lee JH, Menis S, Skog P, Rossi M, Ota T, et al. Precursor Frequency and Affinity Determine B Cell Competitive Fitness in Germinal Centers, Tested With Germline-Targeting HIV Vaccine Immunogens. Immunity (2018) 48(1):133-46.e6. doi: 10.1016/j.immuni.2017.11.023

77. Dosenovic P, Pettersson AK, Wall A, Thientosapol ES, Feng J, Weidle C, et al. Anti-HIV-1 B Cell Responses are Dependent on B Cell Precursor Frequency and Antigen-Binding Affinity. Proc Natl Acad Sci USA (2018) 115 (18):4743-8. doi: 10.1073/pnas.1803457115

78. Peterhoff D, Wagner R. Guiding the Long Way to Broad HIV Neutralization. Curr Opin HIV AIDS (2017) 12(3):257-64. doi: 10.1097/COH.0000000000000356

79. Huang D, Abbott RK, Havenar-Daughton C, Skog PD, Al-Kolla R, Groschel B, et al. B Cells Expressing Authentic Naive Human VRC01-Class BCRs can be Recruited to Germinal Centers and Affinity Mature in Multiple Independent Mouse Models. Proc Natl Acad Sci USA (2020) 117 (37):22920-31. doi: 10.1073/pnas.2004489117

80. Steichen JM LY, Havenar-Daughton C, Pecetta S, Ozorowski G, Willis JR, Toy L, et al. A Generalized HIV Vaccine Design Strategy for Priming of Broadly Neutralizing Antibody Responses. Science (2019) 366(6470): eaax4380. doi: 10.1126/science.aax4380

81. Wang X, Ray R, Kratochvil S, Melzi E, Lin YC, Giguere S, et al. Multiplexed CRISPR/CAS9-Mediated Engineering of Pre-Clinical Mouse Models Bearing Native Human B Cell Receptors. EMBO J (2020) 40(2):e105926. doi: 10.15252/embj.2020105926

82. Abbott RK, Crotty S. Factors in B Cell Competition and Immunodominance Immunol Rev (2020) 296(1):120-31. doi: 10.1111/imr.12861

83. Angeletti D, Kosik I, Santos JJS, Yewdell WT, Boudreau CM, Mallajosyula VVA, et al. Outflanking Immunodominance to Target Subdominant Broadly Neutralizing Epitopes. Proc Natl Acad Sci USA (2019) 116 (27):13474-9. doi: 10.1073/pnas.1816300116

84. Verkoczy L, Alt FW, Tian M. Human Ig Knockin Mice to Study the Development and Regulation of HIV-1 Broadly Neutralizing Antibodies. Immunol Rev (2017) 275(1):89-107. doi: 10.1111/imr.12505

85. Briney B, Sok D, Jardine JG, Kulp DW, Skog P, Menis S, et al. Tailored Immunogens Direct Affinity Maturation Toward HIV Neutralizing Antibodies. Cell (2016) 166(6):1459-70.e11. doi: 10.1016/j.cell.2016. 08.005

86. Tian M, Cheng C, Chen X, Duan H, Cheng HL, Dao M, et al. Induction of HIV Neutralizing Antibody Lineages in Mice With Diverse Precursor Repertoires. Cell (2016) 166(6):1471-84.e18. doi: 10.1016/j.cell.2016.07.029

87. McGuire AT, Gray MD, Dosenovic P, Gitlin AD, Freund NT, Petersen J, et al. Specifically Modified Env Immunogens Activate B-Cell Precursors of Broadly Neutralizing HIV-1 Antibodies in Transgenic Mice. Nat Commun (2016) 7:10618. doi: 10.1038/ncomms10618

88. Duan H, Chen X, Boyington JC, Cheng C, Zhang Y, Jafari AJ, et al. Glycan Masking Focuses Immune Responses to the HIV-1 CD4-Binding Site and Enhances Elicitation of VRC01-Class Precursor Antibodies. Immunity (2018) 49(2):301-11.e5. doi: 10.1016/j.immuni.2018.07.005

89. Dosenovic P, Pettersson AK, Wall A, Thientosapol ES, Feng J, Weidle C, et al. Anti-Idiotypic Antibodies Elicit Anti-HIV-1-Specific B Cell Responses. J Exp Med (2019) 216(10):2316-30. doi: 10.1084/jem.20190446

90. Jardine JG, Kulp DW, Havenar-Daughton C, Sarkar A, Briney B, Sok D, et al. HIV-1 Broadly Neutralizing Antibody Precursor B Cells Revealed by 
Germline-Targeting Immunogen. Science (2016) 351(6280):1458-63. doi: 10.1126/science.aad9195

91. Sok D, Briney B, Jardine JG, Kulp DW, Menis S, Pauthner M, et al. Priming HIV-1 Broadly Neutralizing Antibody Precursors in Human Ig Loci Transgenic Mice. Science (2016) 353(6307):1557-60. doi: 10.1126/ science.aah3945

92. Escolano A, Steichen JM, Dosenovic P, Kulp DW, Golijanin J, Sok D, et al. Sequential Immunization Elicits Broadly Neutralizing Anti-HIV-1 Antibodies in Ig Knockin Mice. Cell (2016) 166(6):1445-58.e12. doi: 10.1016/j.cell.2016.07.030

93. Dosenovic P, von Boehmer L, Escolano A, Jardine J, Freund NT, Gitlin $\mathrm{AD}$, et al. Immunization for HIV-1 Broadly Neutralizing Antibodies in Human Ig Knockin Mice. Cell (2015) 161(7):1505-15. doi: 10.1016/ j.cell.2015.06.003

94. Jardine J, Julien JP, Menis S, Ota T, Kalyuzhniy O, McGuire A, et al. Rational HIV Immunogen Design to Target Specific Germline B Cell Receptors. Science (2015) 340(6133):711-6. doi: 10.1126/science.1234150

95. Jardine JG, Ota T, Sok D, Pauthner M, Kulp DW, Kalyuzhniy O, et al. Priming a Broadly Neutralizing Antibody Response to HIV-1 Using a Germline-Targeting Immunogen. Science (2015) 349(6244):156-61. doi: 10.1126/science.aac5894

96. Havenar-Daughton C, Sarkar A, Kulp DW, Toy L, Hu X, Deresa I, et al. The Human Naive B Cell Repertoire Contains Distinct Subclasses for a Germline-Targeting HIV-1 Vaccine Immunogen. Sci Transl Med (2018) 10(448):eaat0381. doi: 10.1126/scitranslmed.aat0381

97. Stamatatos L, Pancera M, McGuire AT. Germline-Targeting Immunogens. Immunol Rev (2017) 275(1):203-16. doi: 10.1111/imr.12483

98. Haynes BF, Burton DR, Mascola JR. Multiple Roles for HIV Broadly Neutralizing Antibodies. Sci Transl Med (2019) 11(516):eaaz2686. doi: 10.1126/scitranslmed.aaz2686

99. Medina-Ramirez M, Garces F, Escolano A, Skog P, de Taeye SW, Del MoralSanchez I, et al. Design and Crystal Structure of a Native-Like HIV-1 Envelope Trimer That Engages Multiple Broadly Neutralizing Antibody Precursors In Vivo. J Exp Med (2017) 214(9):2573-90. doi: 10.1084/ jem. 20161160

100. Chen X, Zhou T, Schmidt SD, Duan H, Cheng C, Chuang GY, et al. Vaccination Induces Maturation in a Mouse Model of Diverse Unmutated VRC01-Class Precursors to HIV-Neutralizing Antibodies With $>50 \%$ Breadth. Immunity (2021) 54(2):324-39.e8. doi: 10.1016/ j.immuni.2020.12.014

101. Lin YR, Parks KR, Weidle C, Naidu AS, Khechaduri A, Riker AO, et al. HIV1 VRC01 Germline-Targeting Immunogens Select Distinct Epitope-Specific B Cell Receptors. Immunity (2020) 53(4):840-51.e6. doi: 10.1016/ j.immuni.2020.09.007

102. Escolano A, Gristick HB, Abernathy ME, Merkenschlager J, Gautam R, Oliveira TY, et al. Immunization Expands B Cells Specific to HIV-1 V3 Glycan in Mice and Macaques. Nature (2019) 570(7762):468-73. doi: 10.1038/s41586-019-1250-z

103. Ekiert DC, Friesen RH, Bhabha G, Kwaks T, Jongeneelen M, Yu W, et al. Antibody Recognition of a Highly Conserved Influenza Virus Epitope. Science (2009) 324(5924):246-51. doi: 10.1126/science.1171491

104. West AP Jr, Diskin R, Nussenzweig MC, Bjorkman PJ. Structural Basis for Germ-Line Gene Usage of a Potent Class of Antibodies Targeting the CD4Binding Site of HIV-1 Gp120. Proc Natl Acad Sci USA (2012) 109(30): E2083-90. doi: 10.1073/pnas.1208984109

105. Koonin EV. Splendor and Misery of Adaptation, or the Importance of Neutral Null for Understanding Evolution. BMC Biol (2016) 14(1):114. doi: $10.1186 / \mathrm{s} 12915-016-0338-2$
106. Sober E, Wilson DS. Adaptation and Natural Selection Revisited. J Evol Biol (2011) 24(2):462-8. doi: 10.1111/j.1420-9101.2010.02162.x

107. Pievani T, Serrelli E. Exaptation in Human Evolution: How to Test Adaptive vs Exaptive Evolutionary Hypotheses. J Anthropol Sci (2011) 89:9-23. doi: 10.4436/jass.89015

108. Sharp PM, Hahn BH. Origins of HIV and the AIDS Pandemic. Cold Spring Harb Perspect Med (2011) 1(1):a006841. doi: 10.1101/cshperspect.a006841

109. Gould SJ, Lewontin RC. The Spandrels of San Marco and the Panglossian Paradigm: A Critique of the Adaptationist Programme. Proc $R$ Soc Lond B Biol Sci (1979) 205(1161):581-98. doi: 10.1098/rspb.1979.0086

110. Gould SJ. The Exaptive Excellence of Spandrels as a Term and Prototype. Proc Natl Acad Sci USA (1997) 94(20):10750-5. doi: 10.1073/ pnas.94.20.10750

111. Gould SJ, Vrbra ES. Exaptation - A Missing Term in the Science of Form. Paleobiology (1982) 8(1):4-15. doi: 10.1017/S0094837300004310

112. Pigliucci II, Kaplan II. The Fall and Rise of Dr Pangloss: Adaptationism and the Spandrels Paper 20 Years Later. Trends Ecol Evol (2000) 15(2):66-70. doi: 10.1016/S0169-5347(99)01762-0

113. Weiss MA, Nakagawa SH, Jia W, Xu B, Hua QX, Chu YC, et al. Protein Structure and the Spandrels of San Marco: Insulin's Receptor-Binding Surface is Buttressed by an Invariant Leucine Essential for Its Stability. Biochemistry (2002) 41(3):809-19. doi: 10.1021/bi011839+

114. Manhart M, Morozov AV. Protein Folding and Binding can Emerge as Evolutionary Spandrels Through Structural Coupling. Proc Natl Acad Sci USA (2015) 112(6):1797-802. doi: 10.1073/pnas.1415895112

115. Market E, Papavasiliou FN. V(D)J Recombination and the Evolution of the Adaptive Immune System. PloS Biol (2003) 1(1):E16. doi: 10.1371/ journal.pbio.0000016

116. Pancer Z, Cooper MD. The Evolution of Adaptive Immunity. Annu Rev Immunol (2006) 24:497-518. doi: 10.1146/annurev.immunol.24.021605.090542

117. Cooper MD, Herrin BR. How did Our Complex Immune System Evolve? Nat Rev Immunol (2010) 10(1):2-3. doi: 10.1038/nri2686

118. Hirano M, Das S, Guo P, Cooper MD. The Evolution of Adaptive Immunity in Vertebrates. Adv Immunol (2011) 109:125-57. doi: 10.1016/B978-0-12387664-5.00004-2

119. Hirano M, Guo P, McCurley N, Schorpp M, Das S, Boehm T, et al. Evolutionary Implications of a Third Lymphocyte Lineage in Lampreys. Nature (2013) 501(7467):435-8. doi: 10.1038/nature12467

Conflict of Interest: The authors declare that the research was conducted in the absence of any commercial or financial relationships that could be construed as a potential conflict of interest.

The handling editor declared a past collaboration with one of the authors DL.

Publisher's Note: All claims expressed in this article are solely those of the authors and do not necessarily represent those of their affiliated organizations, or those of the publisher, the editors and the reviewers. Any product that may be evaluated in this article, or claim that may be made by its manufacturer, is not guaranteed or endorsed by the publisher.

Copyright (c) 2021 Sangesland and Lingwood. This is an open-access article distributed under the terms of the Creative Commons Attribution License (CC BY). The use, distribution or reproduction in other forums is permitted, provided the original author(s) and the copyright owner(s) are credited and that the original publication in this journal is cited, in accordance with accepted academic practice. No use, distribution or reproduction is permitted which does not comply with these terms. 